\title{
Investigation of UAV Noise Reduction for Electromagnetic Induction Surveying
}

\section{Bjerg, T.; Døssing, A.; Lima Simões da Silva, E.}

\section{Published in:}

Proceedings of the 3rd Conference on Geophysics for Mineral Exploration and Mining

Link to article, DOI:

10.3997/2214-4609.202020149

Publication date:

2020

Document Version

Publisher's PDF, also known as Version of record

Link back to DTU Orbit

Citation (APA):

Bjerg, T., Døssing, A., \& Lima Simões da Silva, E. (2020). Investigation of UAV Noise Reduction for Electromagnetic Induction Surveying. In Proceedings of the 3rd Conference on Geophysics for Mineral Exploration and Mining (pp. 1-5). European Association of Geoscientists and Engineers. https://doi.org/10.3997/2214-4609.202020149

\section{General rights}

Copyright and moral rights for the publications made accessible in the public portal are retained by the authors and/or other copyright owners and it is a condition of accessing publications that users recognise and abide by the legal requirements associated with these rights.

- Users may download and print one copy of any publication from the public portal for the purpose of private study or research.

- You may not further distribute the material or use it for any profit-making activity or commercial gain

- You may freely distribute the URL identifying the publication in the public portal 


\section{Investigation of UAV Noise Reduction for Electromagnetic Induction Surveying}

T. Bjerg ${ }^{1}$, E. Lima Simões da Silva ${ }^{1}$, A. Døssing ${ }^{1}$

${ }^{1}$ Dtu Space

\section{Summary}

Reducing the electromagnetic signal from the UAV by towing the frequency-domain electromagnetic induction instrumentation in a suspension system underneath the UAV, at 6 meters separation the noise from the UAV appears to be neglectable compared to other sources of electromagnetic noise. 


\section{NEAR SURFACE $\triangle$ GEOSCIENCE'20}

\section{EAGE}

\section{Introduction}

Electromagnetic induction methods are widely used for geophysical prospecting. Traditionally, electromagnetic induction is employed for large scale geophysical structures, such as mining, groundwater, and geothermal explorations (Everett, 2013). However, it is also used for near-surface applications such as archaeology and unexploded ordnance (Keiswetter, 2000) (Billings, 2017).

The electromagnetic induction techniques are seen in both airborne and handheld applications. The airborne, typically by helicopter setups, can cover large areas quickly and effectively and is mostly associated with large scale geophysical prospecting. The handheld instrumentation is for the low scale geophysical prospecting, by its smaller instrumental size and a higher special resolution it is well suited for the near-surface targets. Between these two methods, the small unmanned aerial vehicle (UAV) can be used as an instrumentation carrier. A small electromagnetic induction instrument mounted on a UAV can improve the handheld mobility to increase the range and access.

However, the UAV is a source of electromagnetic noise, which is inconvenient for a method such as electromagnetic induction and will generate a high level of noise in the data. i.e. the electromagnetic system needs to be separated from the UAV in a stable manner to be useful for near-surface target detection.

The scope is to reduce the electromagnetic signal from the UAV by moving the instrumentation further away from the UAV, at a certain distance the noise from the UAV can be neglectable compared to other sources of electromagnetic noise.

\section{Survey system}

At DTU Space, the CMAGTRES group has worked on a setup for separating the measuring instruments from the UAV without compromising a steady flight. This is constructed by three main parts: a UAV, an electromagnetic induction instrument as the measuring device, and a suspension to combine these two.

The measuring device is the GEM-2 UAV version from Geophex (Geophex, 2020), related to the GEM2, which have shown useful for near-surface geophysical prospection such as archaeology (Tang, 2018). The GEM-2UAV is shaped like a "ski" and is suited for being towed underneath a UAV, in a similar manner as a classical magnetometer bird. By towing the sensor in a wire suspension underneath the $\mathrm{UAV}$, the measurements can be placed in a noise-free environment. Usually, a long wire suspension will make the bird twist and turn around its axis. By adopting the DTU-patented sensor suspension system (Døssing, et al., 2018), we have created a stable and noise-free towed setup for a UAV-borne electromagnetic sensor system.

The GEM-2UAV is a multi-frequency electromagnetic sensor system using frequency-domain electromagnetic induction (Won, 1996). The frequency-domain electromagnetic induction (FDEM) method uses controlled-source time-varying electromagnetic induction to produce a secondary magnetic field in a conducting target. By measuring, the produced secondary magnetic field GEM$2 \mathrm{UAV}$ will derive in-phase and quadrature data. The unit is parts-per-million (ppm) and is the raw data from GEM-2UAV; this is a sensor-specific unit.

In-phase and quadrature are related to the apparent magnetic susceptibility and the apparent electrical conductivity, respectively (Telford, 1990). GEM-2UAV can operate up to 10 frequencies simultaneous ranging between $25 \mathrm{~Hz}$ and $96 \mathrm{kHz}$. GEM-2 is production for handheld measurements, and it is generally expected to have the lowest measurements noise when doing a walking survey. 


\section{NEAR SURFACE - GEOSCIENCE' 20}

\section{EAGE}

\section{Fieldwork test}

For testing the measured noise produced by the UAV, three tests were carried out: The first was a simple walk with the GEM-2UAV. In the second and third survey, the GEM-2UAV was towed 6meters and 1.5 meters underneath the UAV, respectively. Moving forward, these three surveys will be addressed to as walking survey, UAV survey $6 \mathrm{~m}$, and UAV survey $1.5 \mathrm{~m}$. In Figure 1, the raw data from the three surveys are plotted using the $425 \mathrm{~Hz}$ in-phase as an example of data output. The noise related to this frequency was generally higher than the other output frequencies. In Figure 2, the same raw dataset at $425 \mathrm{~Hz}$ in-phase are plotted continually. Both Figure 1 and 2 indicates low special and time tends. We may therefore conclude that the inhomogeneity in the near-surface is not dominant as compared to the noise level at this frequency. If any geophysical structure was detected at this frequency, a trend would be visual. Some features could maybe be recovered by processing the data, but at the current state, no geophysical structure can be observed.

\section{Raw in-phase $425 \mathrm{~Hz}$ data}

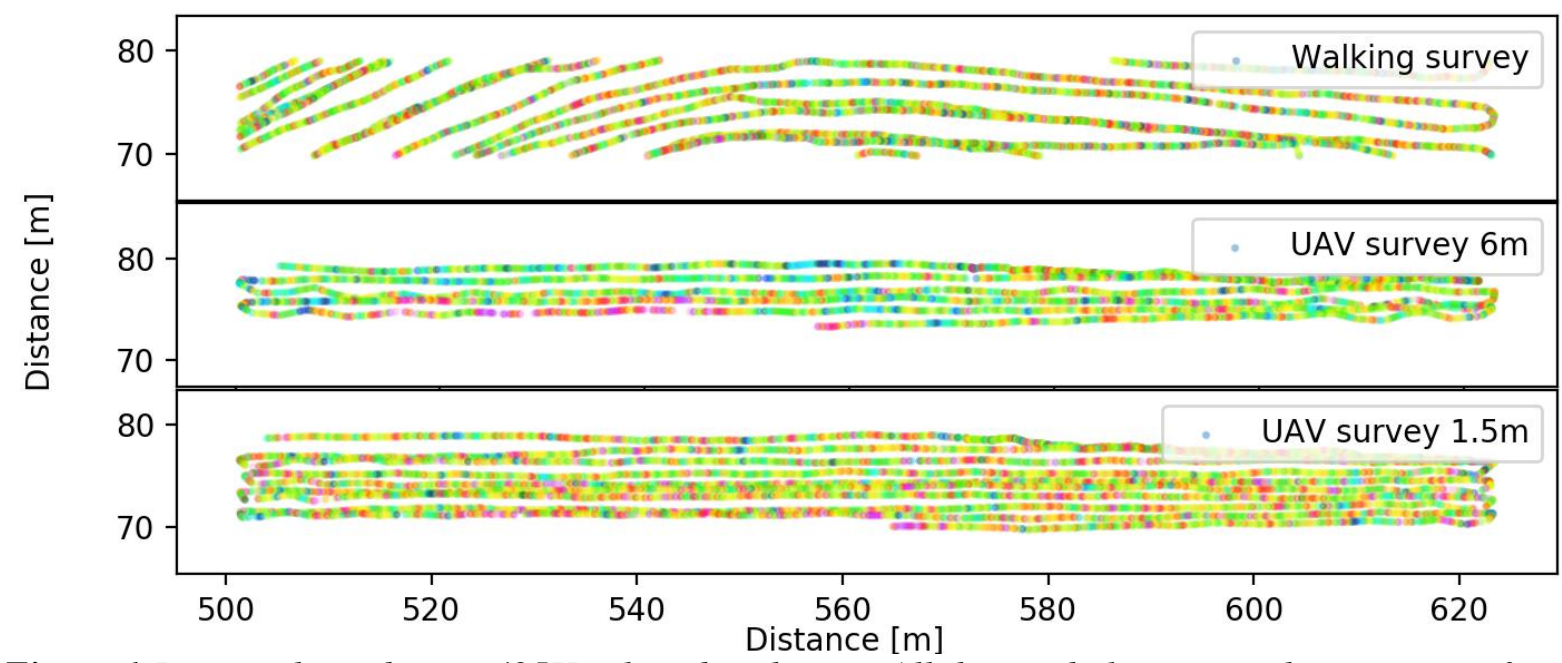

Figure 1 Raw in-phase data at $425 \mathrm{~Hz}$ plotted at the site. All three subplots are in the same area from walking survey, UAV fight with $6 \mathrm{~m}$ and $1.5 \mathrm{~m}$ wire suspension.

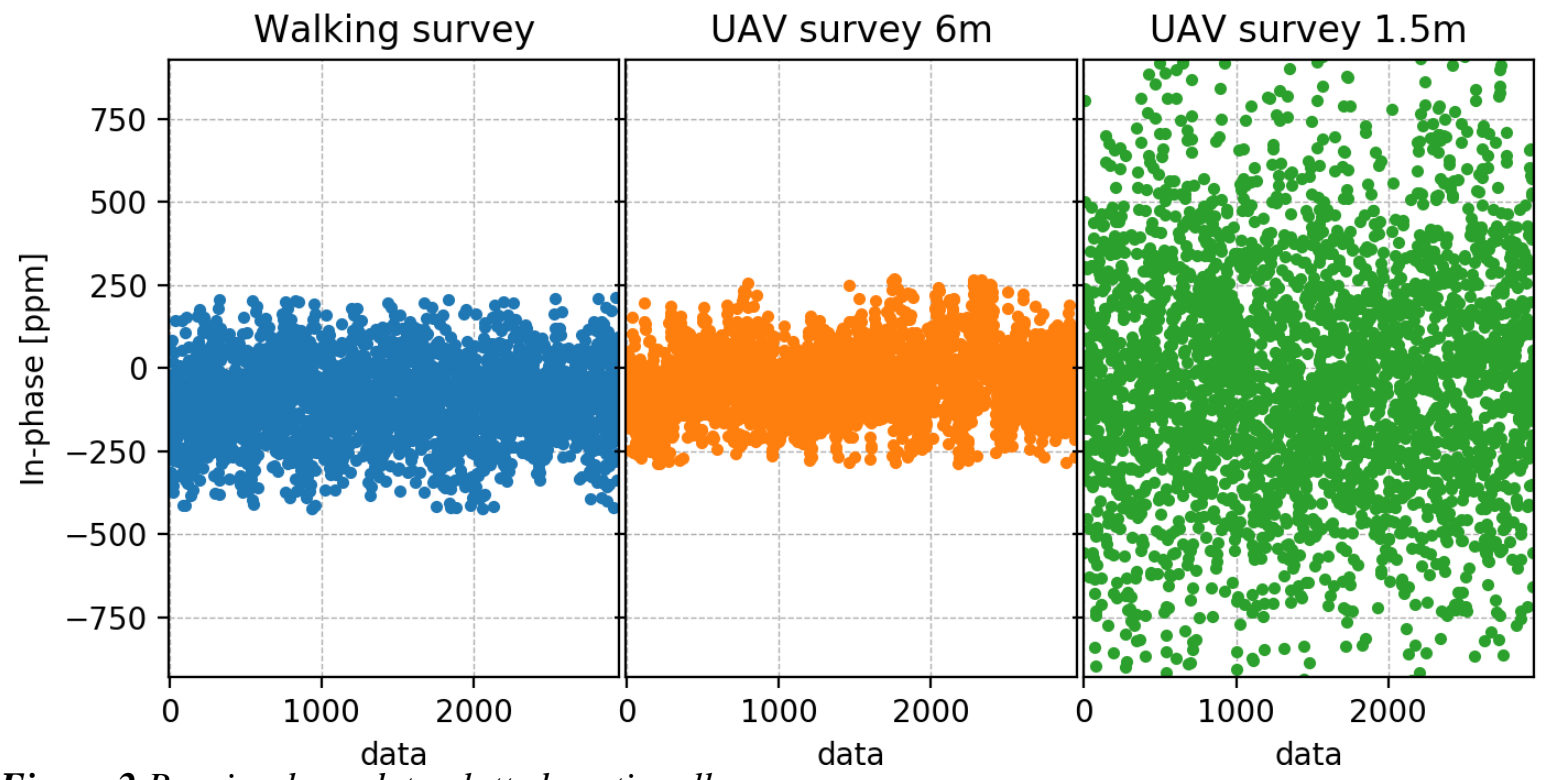

Figure 2 Raw in-phase data plotted continually.

However, an evident difference is observed between the three surveys in Figure 2. The spread of data point between the two UAV measurements is significant, and since the only difference is the length of the wire suspension, it would be reasonable to assume the noise relates to the UAV. This becomes even 


\section{NEAR SUBFACEE GEOSCIENCE'20}

more visible in Figure 3, showing a histogram of the three surveys for raw in-phase data at $425 \mathrm{~Hz}$. The histograms for the three dataset resemble Gaussian distributions, which would be expected from a source of noise. This enables us to rank the noise level from the standard deviation of the data for each frequency although we note that the standard deviation is not a direct measure for the noise, but an indicator. The data distribution is expected to match the magnetic and conducting inhomogeneity at the near-surface, and therefore not desirable to get a lower standard deviation. In Figure 4 the standard deviation is plotted for all the output frequencies for both in-phase and quadrature data. We observe that the UAV survey at $6 \mathrm{~m}$ and the walking survey have similar values while UAV survey at $1.5 \mathrm{~m}$ is significantly higher.

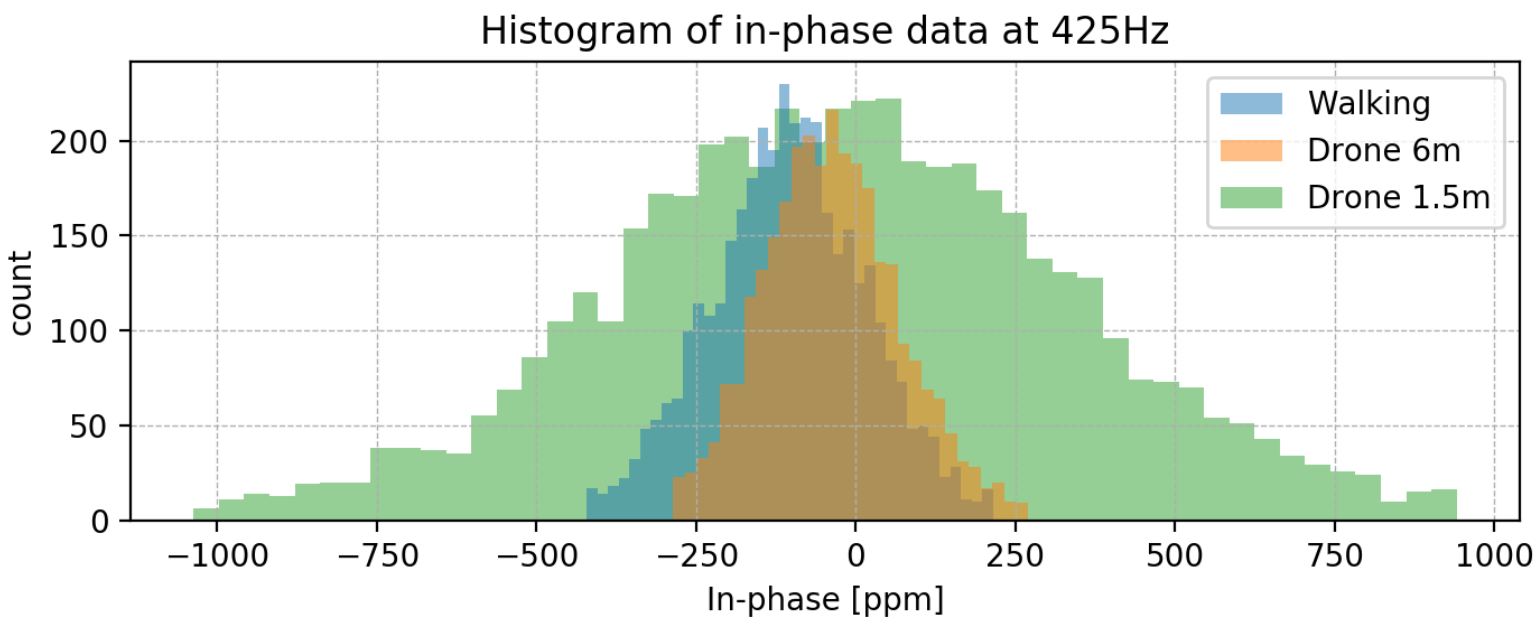

Figure 3 Histogram of the raw in-phase data at $425 \mathrm{~Hz}$ at the site. The three distributions do resemble a Gaussian distribution.

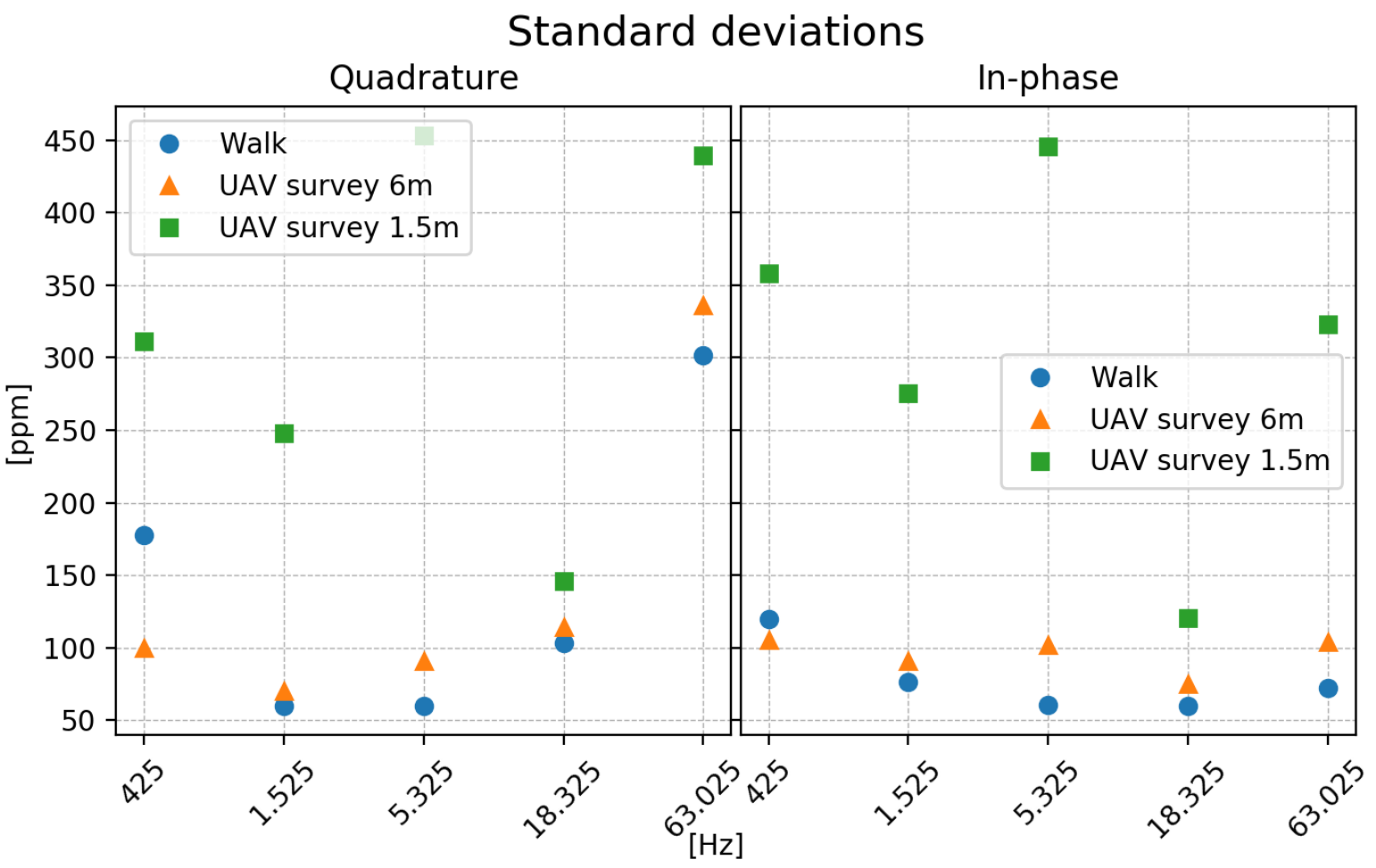

Figure 4 Standard deviation of all measured frequencies for both quadrature and in-phase data. The standard deviation cannot be used directly as a measure of noise level, since the distribution at the certain frequency may reflect some features in the underground. 


\section{NEAR SURFACE - GEOSCIENCE'20}

\section{EAGE}

\section{Conclusion}

The sensor system and test were presented; an early version of the suspension was tested together with the newly acquired GEM-2UAV instrumentation and a UAV (DJI Wind4). Two lengths of suspension were tested, where a walking survey worked as a reference for the UAV based surveys.

Even though the standard deviation cannot be used as a direct measure for the signal to noise ratio, it can be used as an indicator with the walking survey as a baseline. From that perspective, a visual tendency from the standard deviation indicates a low noise impact from the UAV with a $6 \mathrm{~m}$ suspension, while the $1.5 \mathrm{~m}$ suspension makes the UAV noise very dominant.

At the specific output frequency of $425 \mathrm{~Hz}$ a lower standard deviation was observed for the UAV survey with $6 \mathrm{~m}$ suspension than the walking survey. This may indicate that specific output frequencies are UAV noise-free, and produce less noisy dataset than the walking surveys. The $6 \mathrm{~m}$ suspension could potentially be a good case, but it needs further investigation. If all the frequencies result in a signal to noise ratio at the same level as the handheld version, we would gain a lot by the UAV mobility in the less accessible areas and is a strong motivation for further improvements.

\section{Acknowledgements}

This project is founded by A.P. Møller Fonden

\section{References}

Billings, S., \& Beran, L. 2017. Optimizing electromagnetic sensors for unexploded ordnance detection. . s.l. : Geophysics, 82(3), EN25-EN31., 2017.

Døssing, Arne Andreasen and Jakobsen, J. 2018. WIPO Patent Application No. 2017EP68246. 2018.

Everett, M. E. 2013. Near-surface applied geophysics. s.l. : Cambridge University Press, 2013.

Geophex. 2020. http://www.geophex.com/Product\%20-\%20UAV-mounted.htm. 605 Mercury street, Raleigh NC 27603 U.S.A. : s.n., 2020.

Keiswetter, D. A., Won, I. J., Miller, J. M., Bell, T. H., Cespedes, E. R., \& O'Neill, K. 2000. Electromagnetic induction spectroscopy for detecting and identifying buried objects. s.l. : In Detection and Remediation Technologies for Mines and Minelike, 2000.

Tang, P., Chen, F., Jiang, A., Zhou, W., Wang, H., Leucci, G., ... \& Masini, N. 2018. Multi-frequency electromagnetic induction survey for archaeological prospection: approach and results in Han Hangu Pass and Xishan Yang in China. . s.l. : Surveys in Geophysics, 2018.

Telford, W. M., Telford, W. M., Geldart, L. P., Sheriff, R. E., \& Sheriff, R. E. 1990. Applied geophysics. s.l. : Cambridge university press, 1990.

Won, I. J., Keiswetter, D. A., Fields, G. R., \& Sutton, L. C. 1996. GEM-2: A new multifrequency electromagnetic sensor. . s.l. : Journal of Environmental and Engineering Geophysics, 1(2), 129-137., 1996. 